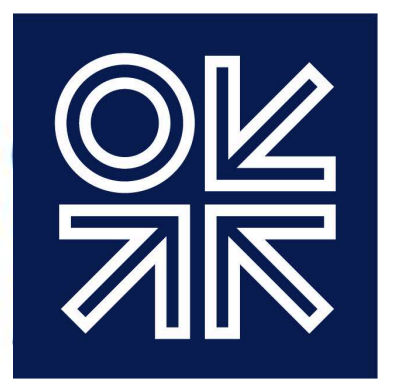

THE OXFORD INSTITUTE FOR ENERGY STUDIES

\title{
LNG Spot Price Forecasting and the Futures Curve
}

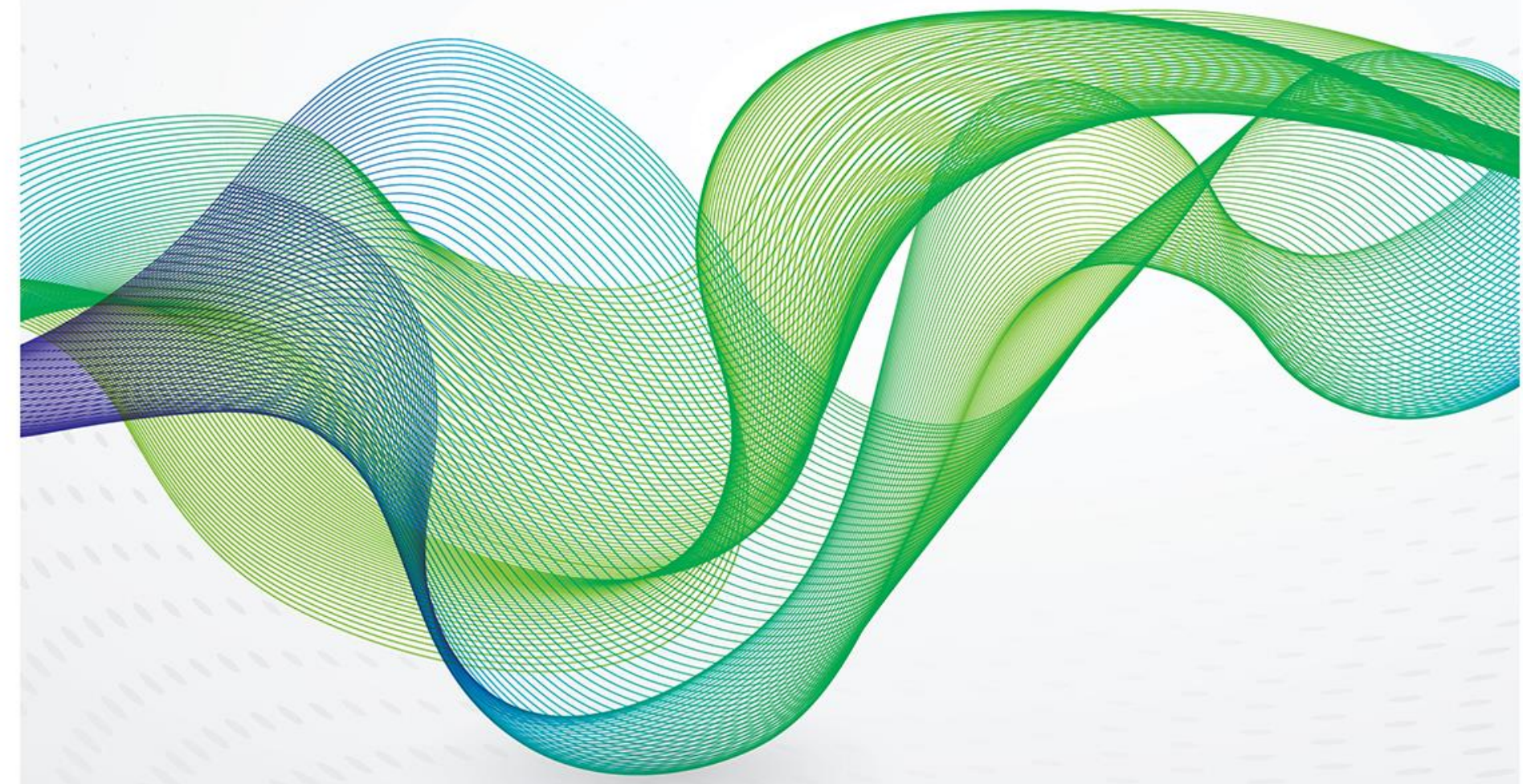


The contents of this paper are the author's sole responsibility. They do not necessarily represent the views of the Oxford Institute for Energy Studies or any of its members.

Copyright $\odot 2019$

\section{Oxford Institute for Energy Studies}

(Registered Charity, No. 286084)

This publication may be reproduced in part for educational or non-profit purposes without special permission from the copyright holder, provided acknowledgment of the source is made. No use of this publication may be made for resale or for any other commercial purpose whatsoever without prior permission in writing from the Oxford Institute for Energy Studies.

ISBN 978-1-78467-140-2

DOI: https://doi.org/10.26889/9781784671402 

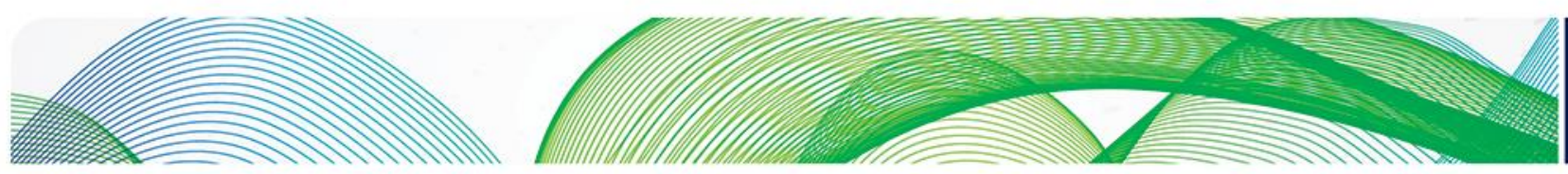
애잦

\section{Contents}

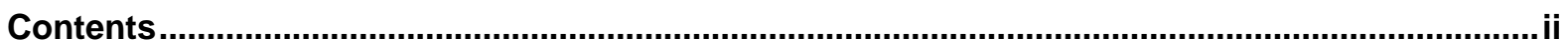

Figures

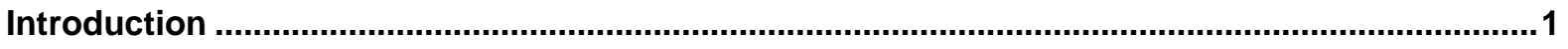

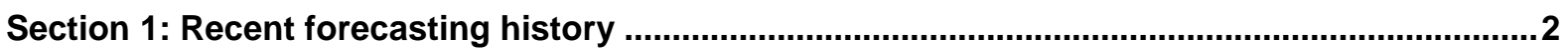

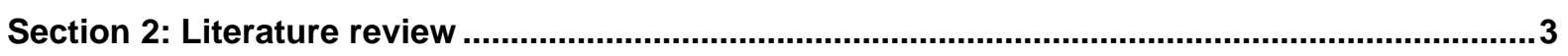

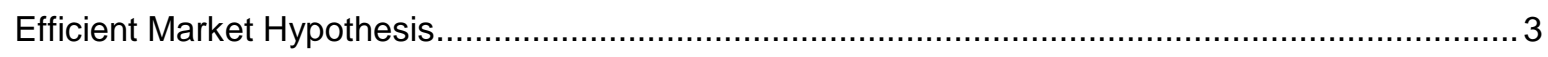

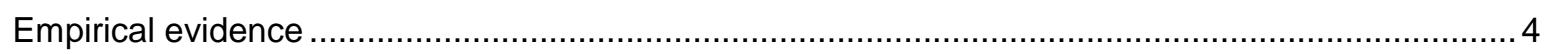

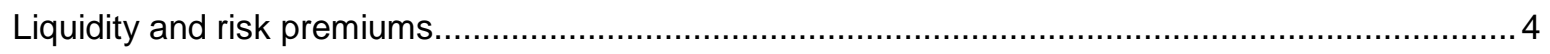

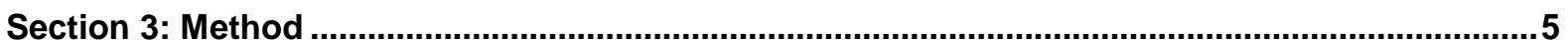

Data

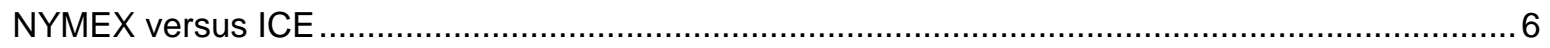

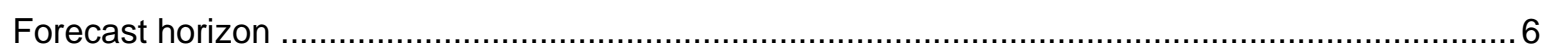

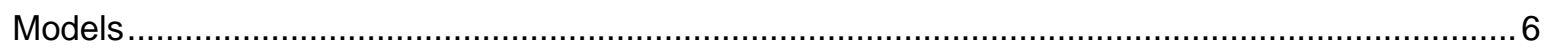

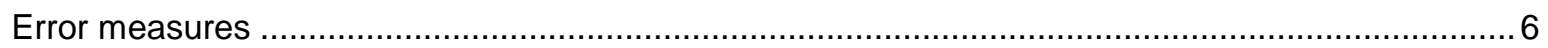

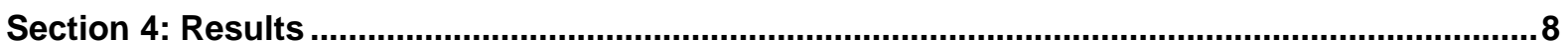

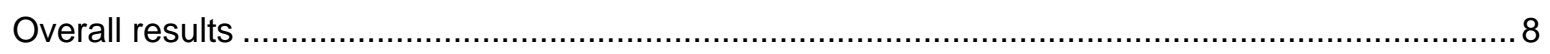

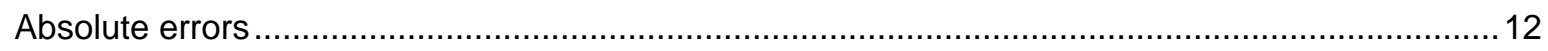

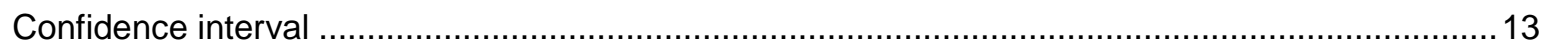

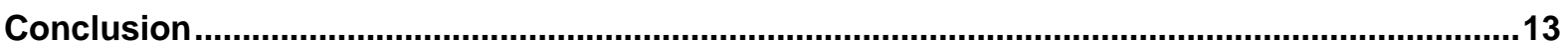

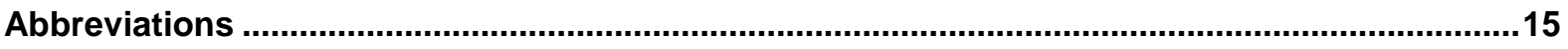

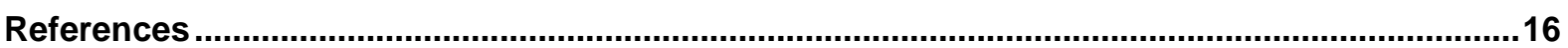

\section{Figures}

Figure 1: Asian LNG spot price and LNG imports of key Asian buyers, monthly ................................

Figure 2: Relative mean absolute error of a futures-based forecast ................................................ 8

Figure 3: Rolling futures-based forecast at selected time horizons (days) .........................................

Figure 4: Open futures contracts on the New York Mercantile Exchange on selected dates .............10

Figure 5: Asian LNG futures curves on selected dates and Asian LNG spot prices ..........................10

Figure 6: Relative mean absolute error of a futures-based forecast, backwardation versus contango

Figure 7: Percentage of futures-based forecasts that beat the naïve forecast................................. 12

Figure 8: Mean absolute error and mean absolute percentage error of a futures-based forecast ........12

Figure 9: Confidence interval (68 per cent) around a futures-based forecast .....................................13 

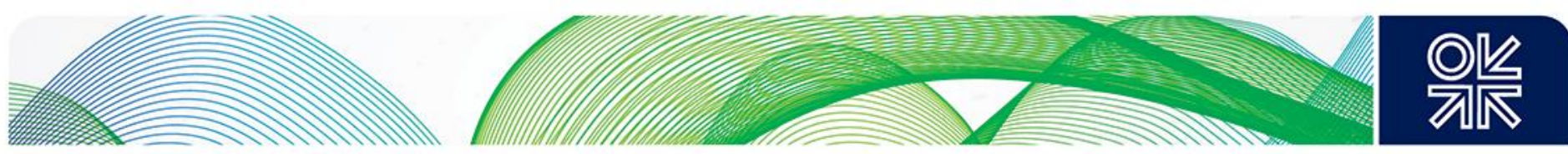

\section{Introduction}

LNG spot prices in Asia have defied expectations over the past few years. During 2016 and 2017, LNG markets were widely expected to enter a period of overcapacity, resulting in a long period of low LNG spot prices in Asia. Instead, Asian LNG spot prices increased quickly due to surging demand, particularly in China, and delays in bringing new LNG projects online. In 2018, fears of overcapacity began to recede as LNG prices climbed further, and discussion turned to the potential for a future supply crunch. However, by the time of writing in early April 2019, LNG spot prices in Asia had surprised again, having fallen rapidly to record lows. ${ }^{1}$

This paper aims to evaluate the accuracy of using the Asian LNG futures price - the current price of LNG for delivery at a specified future date - to forecast the Asian LNG spot price. ${ }^{2}$ The assessment of forecasting performance has to be a relative one, measuring how different forecasting approaches perform against others (Bowman \& Husain 2004). This paper compares futures-based forecasts against a literature benchmark for testing forecasting methodologies - the 'naïve' or 'no change' forecast, under which future spot prices are forecast to equal the most recent spot price. ${ }^{3}$

The key findings of this paper are as follows:

- The Asian LNG futures price has displayed some predictive power relative to a naïve forecast for time horizons of around five months or less. However, a naïve forecast has performed better than a futures-based forecast for time horizons of over six months.

- The deterioration in the forecast accuracy of the LNG futures curve may be explained by uncertainties inherent in longer forecast horizons, declining liquidity in the futures market, and/or the presence of an increasing premium to hedge risk over longer time periods.

- Average forecast errors are substantially lower when the futures curve is in backwardation than when the futures curve is in contango. ${ }^{4}$ However, these averages obscure the fact that the futures curve has frequently detected upward movements in LNG spot prices when it is in contango, suggesting it can sometimes be a useful indicator of a tightening market.

The paper is divided into four sections. Section 1 looks at forecasts for Asian LNG spot prices over the past few years. Section 2 discusses why the Asian LNG futures price might contain information about future spot prices and reviews the commodity price forecasting literature relevant to this paper. Section 3 outlines the methodology used in the paper, while Section 4 discusses the paper's key findings.

\footnotetext{
${ }^{1}$ Many thanks to Professor Tatsuyoshi Okimoto for his suggestions and comments. Tatsuyoshi Okimoto is Associate Professor of Economics and Finance at the Crawford School of Public Policy at the Australian National University.

${ }^{2}$ Broadly speaking, a commodity purchased on the spot market is for immediate delivery (although in practice the time until delivery varies depending on the market), whereas a commodity purchased in the futures market is for delivery at a specified future time.

${ }^{3}$ Futures-based and naïve forecasting approaches are discussed in Section 3.

${ }^{4}$ For the purpose of this paper, the futures curve is in contango when the futures price is higher than the spot price, and in backwardation when the futures price is lower than the spot price.
} 

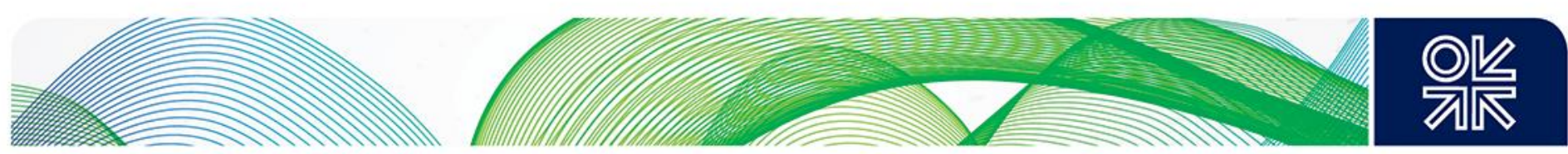

\section{Section 1: Recent forecasting history}

The business model that evolved over the first few decades of the LNG industry's existence was based on inflexible, long-term contracts between buyers and sellers, under which LNG prices were linked to the price of oil. During the mid-2000s, spot and short-term trade in Asia - defined as transactions on contracts of four years or less - gradually increased. In 2018, spot and short-term trade in Asia totalled 72 million tonnes, around 30 per cent of LNG trade in the region, with the majority of this probably pure spot trades (GIIGNL 20195).

Movements in LNG spot prices have proven difficult to anticipate over the past few years. Between 2009 and 2015, the LNG industry embarked on an expansion of an unprecedented scale (Corbeau \& Flower 2016, Henderson et al. 2016). Final investment decisions (FIDs) were taken for 19 new projects with a combined capacity of 152 million tonnes per annum. The expansion was encouraged by expectations of rapidly growing gas demand (particularly in Asia), high oil prices (to which LNG contract prices in Asia are linked) and, in the wake of Fukushima disaster in 2011, high LNG spot prices.

Events, however, did not unfold as anticipated. Gas demand in Asia did not take off as expected and both oil and LNG spot prices fell from 2014. In 2016, a period of overcapacity in LNG markets appeared to have arrived. Asian LNG spot prices fell as low as US\$4.10/MMBtu, averaging US\$5.80/MMBtu for the year, well down on levels of over US $\$ 20 / M M B t u$ of just a few years earlier.

These events led to predictions of a long period of deep overcapacity in LNG markets, potentially lasting through until the mid-2020s or even later. Overcapacity was expected to result in a protracted period of low spot prices in Asian LNG markets. Low spot prices were thought likely even if oil prices rebounded, with spot and oil-linked contract prices in Asia potentially diverging (FGE 2016). Forecasts over 2016 and 2017 typically put Asian LNG spot prices in the US\$5-7/MMBtu range until the end of the decade, if not into the early to mid-2020s (FGE 2016, Macquarie 2017, Bloomberg New Energy Finance 2017, Macdonald-Smith 2017, Department of Industry, Innovation and Science 2017).

In the end, however, this period of low LNG spot prices in Asia was short-lived. LNG spot prices increased rapidly in late 2017 and, after briefly falling back at the start of 2018, increased and subsequently stabilised at levels well above what was expected during 2016 (Figure 1). In 2018, LNG spot prices averaged US $\$ 10 / \mathrm{MMBtu}$ - well above the prices of US $\$ 5-7 / \mathrm{MMBtu}$ predicted by many forecasters.

A combination of demand-side and supply-side factors led to LNG markets tightening unexpectedly in late 2017 and 2018 (Department of Industry, Innovation and Science 2018). In Asia, LNG demand increased more rapidly than many had anticipated. After several years of flat or subdued LNG demand growth, China's LNG imports took off in 2017 as the country sought to reduce air pollution by encouraging gas use in place of coal. Between 2016 and 2018, China's LNG imports more than doubled, increasing from 24 million tonnes to 54 million tonnes (Figure 1). South Korea's LNG imports also climbed quickly over the same period, reaching a record high of 45 million tonnes in 2018 , as the country faced a number of nuclear shutdowns and the government introduced policies that supported gas use in electricity generation. Meanwhile, Japan's LNG imports remained relatively stable during 2017 and 2018, rather than falling as some had predicted, with delays in restarting nuclear reactors supporting gas demand. On the supply-side, delays in bringing LNG projects online in both Australia and the United States gave time for strong demand growth to close the gap on supply capacity.

\footnotetext{
${ }^{5}$ Pure spot trades accounted for 79 per cent of spot and short-term trades globally in 2018, although no such breakdown is available for Asia.
} 

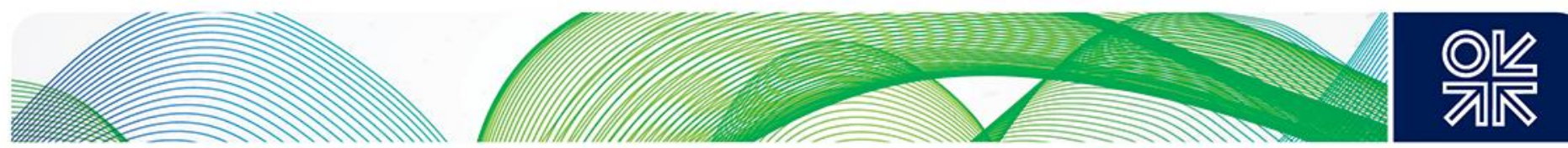

Figure 1: Asian LNG spot price and LNG imports of key Asian buyers, monthly

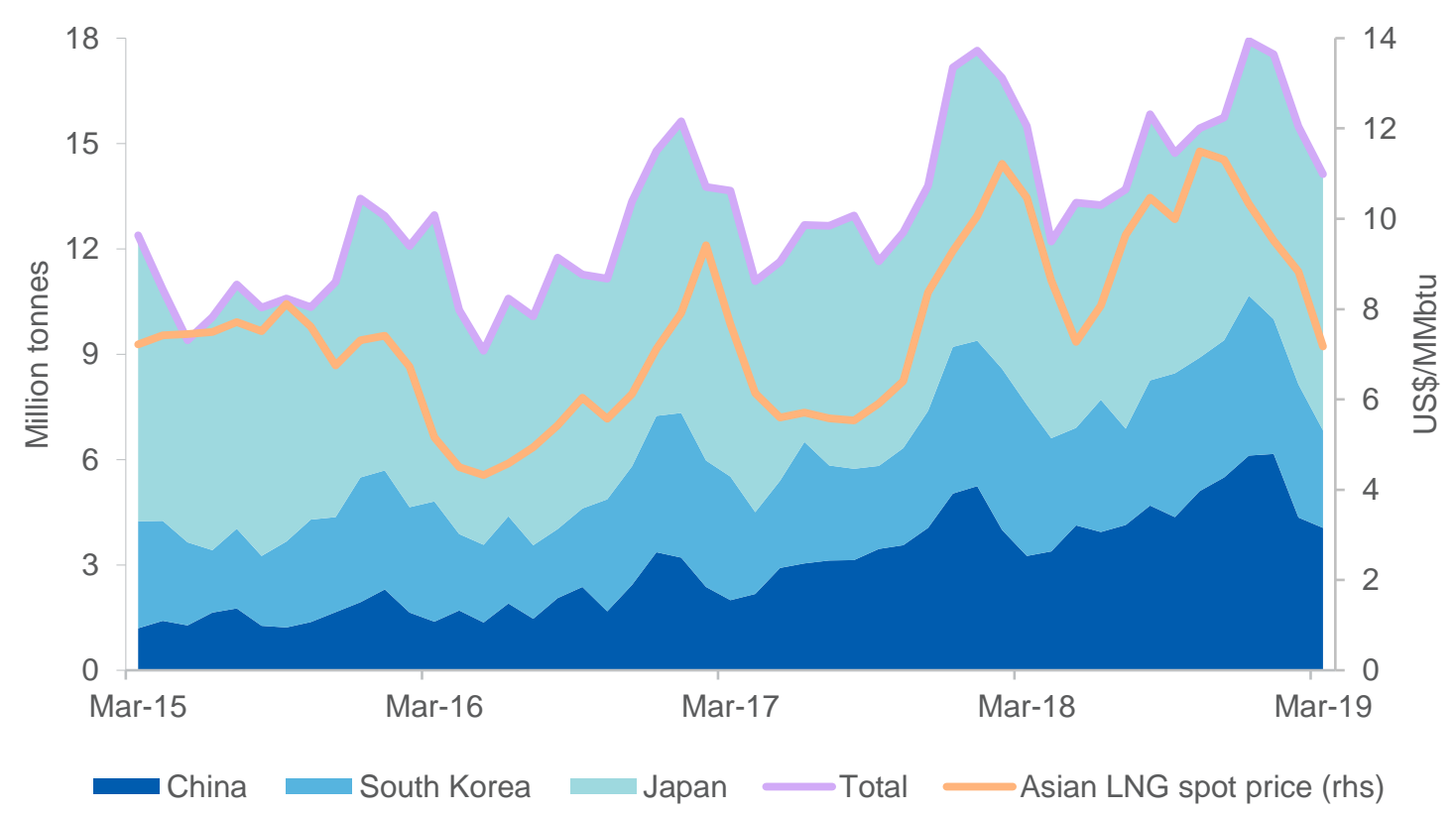

Source: Argus

Notes: Settlement price for each contract month is shown

With LNG spot prices remaining relatively high in 2018, some forecasters began to retreat from predictions of overcapacity in LNG markets and low LNG spot prices. Discussion instead turned to the possibility of an emerging supply crunch from the early to mid-2020s. However, by the time of writing in April 2019, LNG spot prices had surprised again. Spot prices fell sharply from late 2018, including through the 2018-19 northern hemisphere winter, a time at which they would usually escalate due to higher seasonal demand. In early April 2019, LNG spot prices in Asia were at their equal lowest level on record at US\$4-4.50/MMBtu.

In light of recent forecasting history, it is worth considering if and when the futures curve might be a useful tool for forecasting LNG spot prices in Asia. Processes of price formation in Asian LNG spot markets are complex and are influenced by a wide range of factors, including hub prices in Europe and the US, coal-to-gas switching, seasonal demand, storage levels and oil prices. However, while processes of price formation in Asian LNG spot markets are complicated, the basic theory behind using the LNG futures curve as a forecast is that expectations of how all these factors will feed into LNG spot prices are embodied in the futures price. In other words, a futures-based forecast could help to cut through some of the complexity associated with price formation processes in the region.

\section{Section 2: Literature review}

\section{Efficient Market Hypothesis}

The view that the futures price is the best forecast for the spot price is an implication of Efficient Market Hypothesis or EMH (Chin \& Coibion 2014). In its simplest form, EMH suggests that futures prices reflect all available information about future spot prices. If futures prices did not reflect all available information, then market participants would use such information to buy and sell futures contracts in anticipation of securing a profit, and futures prices and expected future spot prices would therefore converge. Under the assumptions of risk neutrality and rationality of market participants (Westerlund et al 2014), EMH implies that the futures price - the current price of an asset for delivery at a specified date - is equal 

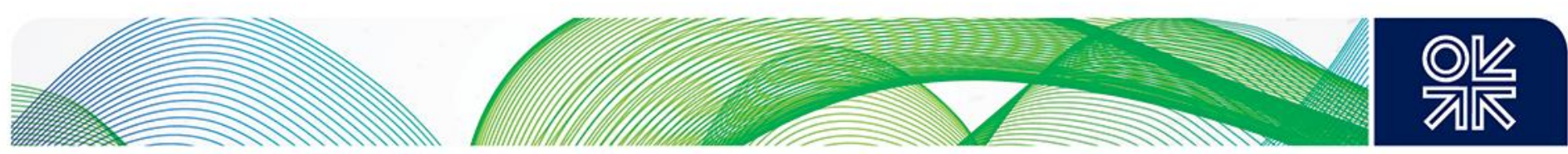

to expected future spot price, as specified in equation (1). $F_{t, h}$ is the futures price at time $t$ for horizon $h$, $E_{t}$ indicates expectations at time $t$, and $S_{t+h}$ is the spot price at maturity date $t+h$.

$$
F_{t, h}=E_{t}\left[S_{t+h}\right]
$$

\section{Empirical evidence}

The empirical evidence on whether futures are a useful tool for predicting spot prices is mixed. One group of studies found that futures prices are a useful guide for forecasting spot prices. Reichsfeld and Roache (2011) tested a futures-based forecasting approach for 10 commodities (agricultural, energy and minerals), concluding that futures are 'hard to beat'. Their study found that, for most commodities, futures prices performed as least as well as a naïve forecast for most time horizons under two years and, in most cases, did significantly better.

Similarly, Reeve and Vigfusson (2011) looked at 15 different commodity markets (agricultural, metals and energy), finding that the futures price has generally outperformed a naïve forecast for forecast horizons of three months and one year, although not by a large margin. Chin and Coibion (2014) suggest that futures prices for agricultural and energy commodities (although notably not for oil) contain some predictive content. Studies by Bowman and Hussain (2004) and Jin (2016) also suggest that futures prices have some predictive power.

Another group of studies - mostly focused on oil markets - finds no evidence to support the idea that futures prices provide guidance on future spot prices. Alquist, Kilian and Vigfusson (2011), for example, found that futures prices are no more accurate predictors of oil spot prices than a naïve forecast for time horizons of less than 12 months. Bopp and Lady (1991), Knetsch (2007) and Alquist and Kilian (2010) reach similar conclusions around the predictive value of oil futures prices. Chin and Coibion (2014) suggest that futures for base and precious metals are of little value for forecasting spot prices.

While the predictive power of LNG futures prices has not been examined before, there is literature on natural gas futures focused on Henry Hub prices in the United States. Reichsfeld and Roache's 2011 study found that Henry Hub futures prices have outperformed a naïve forecast for time horizons of up to a year, but that a naïve forecast records lower forecast errors at a two year time horizon. Reeve and Vigfusson's 2011 study found that Henry Hub futures have outperformed a naïve forecast at time horizons of three months ahead and one year ahead, although the accuracy of futures was substantially better at a three month horizon than at one year. Similarly, Chin and Coibion (2013) found that natural gas futures were more accurate than a naïve forecast for periods of less than a year, and that futures performed better at shorter time horizons than at longer ones. A key theme from these studies is that the predicative power of futures deteriorates as the forecast horizon lengthens $-a$ finding which is echoed in this paper. However, much like the broader literature, the evidence on the utility of natural gas futures as a forecast is split. Mishra and Smyth (2016) find that Henry Hub futures prices do not perform any better than a naïve forecast for time horizons of four months or less.

Part of the reason the literature is divided is that it covers many different markets, the availability of data can differ from commodity to commodity, forecast accuracy is evaluated at different time horizons, and the historical data used varies across studies. Further complicating matters is that there are different methods for testing the predictive value of futures prices. However, there are also two factors that might help explain some of the differences in the forecast accuracy of the futures curve across different markets: liquidity and risk premiums.

\section{Liquidity and risk premiums}

One factor that can affect the accuracy of a futures-based forecast is liquidity - that is, the amount of trading activity - in the futures market. Theoretically, futures prices in more liquid markets should more accurately predict future spot prices because they are capturing the expectations of many market participants. Reichsfeld and Roache (2011) suggest that lower liquidity at the back end of the futures curve might account for the deterioration in forecast performance of futures observed in their study. 

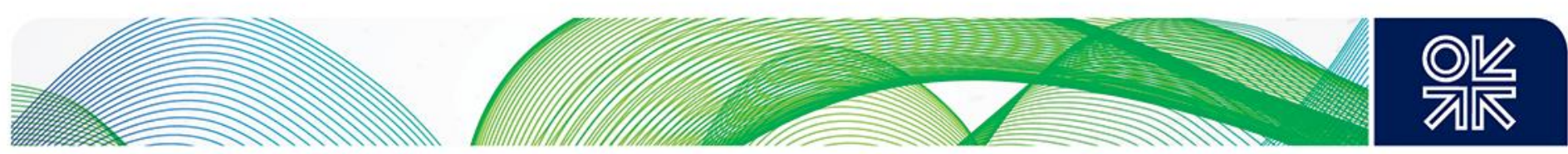

However, empirical work by Chin \& Coibion (2013) and Algieri and Kalkuhl (2014) suggests that liquidity only explains a small percentage of errors in a futures-based forecast.

Another factor that can affect the accuracy of a futures-based forecast is the presence of a risk premium in the futures price. Both producers and consumers use futures contracts to manage risk. For example, a producer may enter a futures contract as a form of insurance against a decline in the spot price. Likewise, consumers may want to purchase a commodity in the futures market to insure against an increase in prices. In order for a producer or a consumer to lock in a price in the future, investors require a return to entice them to take the offsetting position in a futures contract. A risk premium is the compensation that purchasers of futures contracts expect for taking on another party's exposure to fluctuations in the spot price of a commodity.

The effect of a risk premium on a futures-based forecast is captured in the risk premium model, which splits the futures price into the expected spot price at the maturity of the futures contract and a risk premium (Hambur \& Stenner 2017), as shown in equation (2). $F_{t, h}$ is the futures price at time $t$ for horizon $h, E_{t}$ indicates expectations at time $t$, and $S_{t+h}$ is the spot price at maturity date $t+h$.

$$
F_{t, h}=E_{t}\left[S_{t+h}\right]-\text { Risk } \text { premium }_{t, h}
$$

According to net hedging pressure theory, if the hedging activity of consumers (who are insuring against an increase in prices) outweighs that of producers (who are insuring against a decrease in prices), the futures price will need to be above the expected future spot price to attract investors: investors are agreeing to sell a commodity in the future at a set price, expecting to be able to obtain this commodity from the market at a lower price than for which they sold it. This implies a negative risk premium. The opposite holds if the hedging activity of producers is greater than that of consumers.

Risk premiums are thought to be larger (in absolute terms) for longer-maturity contracts, as investors require higher returns over longer time periods (Hambur \& Stenner 2017). Movassagh and Modjtahedi (2005) suggest that natural gas futures contain a risk premium, which grows as the forecast horizon lengthens, and biases their use as a forecast, although Chernenko et al (2004) find no such evidence.

\section{Section 3: Method}

\section{Data}

The Asian LNG futures price used in this paper is the LNG Japan/Korea Marker (Platts), also known as the JKM futures price. ${ }^{6}$ The futures price for a given month (known as the 'contract month') represents the price for a cargo delivered during that month. For example, the futures price for the contract month of July 2019 represents the price for LNG delivered in July 2019. This paper has looked at the forecast accuracy of daily futures prices for contract months between October 2014 and April 2019 (inclusive).

The JKM futures contract for a given month is settled based on the average Japan/Korea Marker (JKM) spot price, produced by Platts, between the $16^{\text {th }}$ calendar day of the month that is two months prior to the futures contract month, and the $15^{\text {th }}$ calendar day of the month that is one month prior to the futures contract month (the settlement period). More roughly put, the futures price is settled at the average spot price between two and six weeks before the contract month. This paper, therefore, tests whether the JKM futures price for a given contract month is a good forecast for the average spot price during the settlement period. For example, the paper evaluates whether the JKM futures price for the contract month of July is a good forecast for the average spot price between 16 May and 15 June.

It is worth noting that final settlement under a JKM futures contract is on a cash basis; that is to say, on expiry of the futures contract, the buyer does not receive the underlying commodity, but rather pays or

\footnotetext{
${ }^{6}$ Korea refers to South Korea.
} 

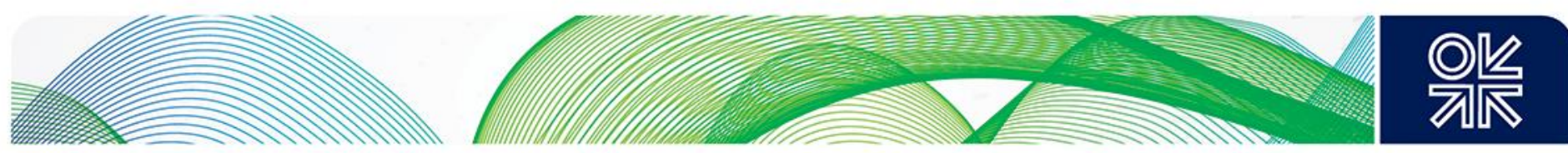

receives the difference between the purchase price of the contract and the price of the futures contract on settlement (CME Group 2019).

Ideally, the JKM spot price would be the Asian LNG spot price used in this paper. However, given that the author did not have access to the Platts JKM spot price, Argus Northeast Asian (ANEA) LNG spot price data was used. The settlement price series used in this paper was derived from the four halfmonth ANEA LNG spot price series, following the Platts JKM spot price methodology (i.e. by taking an average price for the two half month cycles constituting the settlement period). The ANEA LNG spot price series are constructed in a very similar way to the Platts JKM series: they are published in the same units (US $\$ / M M B t u)$, based on the price of cargoes of the same minimum size delivered to the same countries (Japan, South Korea, China and Taiwan), and roll over on the same day each month. Given that all Asian LNG spot price series follow each other very closely, and the magnitude of the forecast errors found in this paper, using ANEA spot data in place of the JKM is not likely to have affected the paper's key findings substantially.

\section{NYMEX versus ICE}

JKM futures contracts are traded daily on several exchanges, but the most established is the Intercontinental Exchange (ICE), followed by the New York Mercantile Exchange (NYMEX), which is part of the Chicago Mercantile Exchange (CME). Although the ICE is the more liquid of the two exchanges, the JKM futures price on the NYMEX was used in this study. However, given that prices at both exchanges are almost identical, the choice of exchange is unlikely to have had any influence on the findings of this study.

\section{Forecast horizon}

The forecast horizon for the futures price is given as the number of days until the start of the 30-day period which determines the average JKM spot price for the contract month (the settlement period). For example, the futures price on 15 May is taken to be the one-day ahead forecast for the average spot price between 16 May and 15 June.

\section{Models}

Two forecasting approaches are assessed in this paper: a futures-based forecasting approach and a 'naïve' or 'no change' forecasting approach. The naïve forecasting approach can be specified as in (3), where $S_{t}$ is the spot price at time $t$ and $h$ is the number of days until the beginning of the settlement period for the contract month being forecast.

$$
S_{t}=S_{t+h}
$$

Using the same notation, the futures-based forecasting model can be specified as in equation (4). In short, the naïve forecast is for future spot prices to be equal to the current spot price, whereas the futures-based approach predicts that future spot prices will be equal to the futures price.

$$
F_{t, h}=S_{t+h}
$$

\section{Error measures}

There are numerous measures for evaluating forecast accuracy. Hyndman and Koehler (2006) divide these measures into four main categories: scale-dependent measures; measures based on percentage errors; measures based on relative errors; and relative measures. All measures have strengths and weaknesses, and different error measures are appropriate in different situations (Armstrong \& Collopy 1992).

Broadly following Armstrong (2001), the following notation is used for error measures:

- $\mathrm{n}$ is the naïve (no change) forecast,

- $f$ is the futures-based forecast, 

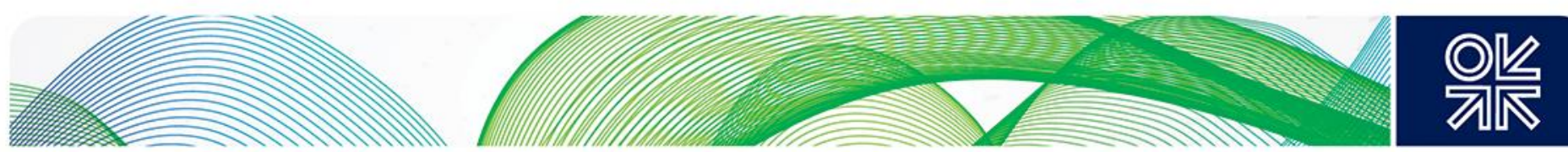

- $m$ is the forecasting method (either futures-based or naïve),

- $\mathrm{h}$ is the horizon being forecast,

- $F_{m, h}$ is the forecast from method $m$ for horizon $h$,

- $A_{h}$ is the actual value at horizon $h$, and

- $\mathrm{N}$ is the total number of forecasts at the relevant time horizon.

The scale-dependent error method used in this paper is the Mean Absolute Error (MAE), which is the absolute average difference between the forecast value and the actual value in dollar terms at a particular time horizon. A downside of the MAE is that it can be heavily influenced by outliers.

$$
M A E_{m, h}=\frac{1}{N} \sum_{i=1}^{N}\left|F_{m, h}-A_{h}\right|
$$

One of the two relative measures used in this paper is the relative MAE, which provides a straightforward way of comparing the performance of the futures-based forecast and the naïve forecast. When the relative $M A E<1$, the futures-based forecast is better than the naïve forecast. When the relative MAE > 1, the naïve forecast outperforms the futures-based approach.

$$
\text { Relative } M A E_{f, h}=\frac{M A E_{f, h}}{M A E_{n, h}}
$$

The second relative measure employed is the Per Cent Better (PB) measure. The PB measure expresses how often the futures-based forecast outperforms the naïve forecast as a percentage. An advantage of the PB measure is that it is not sensitive to outliers. However, a downside is that it does not capture the magnitude of errors for the forecasts being compared.

$$
P B_{f, h}=\frac{\sum_{n=1}^{N} j_{f}}{N} \times 100
$$

Where $A E$ is the absolute error of a single forecast and

$$
j_{f}=\left\{\begin{array}{l}
1 \text { if } A E_{f}<A E_{n} \\
0 \text { if } A E_{f} \geq A E_{n}
\end{array}\right.
$$

The percentage-based error method used in this paper is the Mean Absolute Percentage Error (MAPE). One disadvantage of the MAPE is that it favours under-forecasting; for forecasts with the same absolute error, forecasts above the actual have a higher percentage error than forecasts below the actual (Armstrong 1992).

$$
M A P E_{m, h}=\frac{1}{N} \sum_{i=1}^{N}\left|\frac{F_{m, h}-A_{h}}{A_{h}}\right|
$$

The Root Mean Squared Error (RMSE) is also used in this paper, given that its statistical properties allow for the construction of a confidence interval around forecasts. Assuming errors are normally distributed, there is a 68 per cent chance that actual prices will fall within one RMSE of the forecast, and a 95 per cent chance that actual prices will fall within two RMSEs of the forecast (Reserve Bank of Australia 2012).

$$
R M S E_{m, h}=\sqrt{\left(\frac{\sum_{n=1}^{N}\left(F_{m, h}-A_{h}\right)^{2}}{N}\right)}
$$



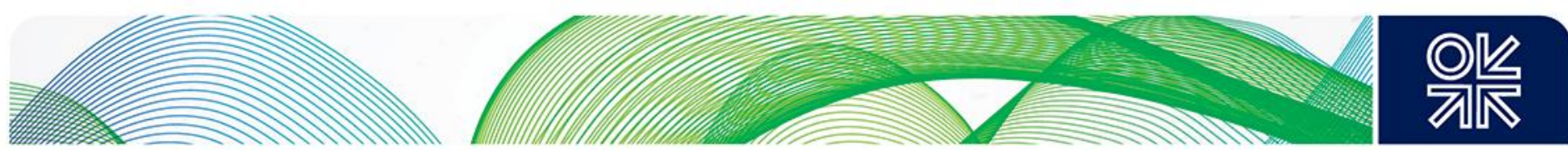

\section{Section 4: Results}

\section{Overall results}

A key finding of this paper is that a futures-based forecast has been more accurate than the naïve forecast for time horizons of up to around 150 days, or five months. The futures curve consistently performs better than a naïve forecast for time horizons of around 120 days or less (four months), but is only marginally better than a naïve forecast in the fifth month. After around 180 days (six months), the naïve forecast consistently outperforms the futures-based forecast. This suggests that, for shorter forecast horizons, the futures price can give some indication of where LNG spot prices are headed. Figure 2 shows the relative mean absolute error of the futures-based forecast. A score of less than one indicates that the futures-based approach has outperformed the naïve forecast, and a score of over one indicates the opposite.

Figure 2: Relative mean absolute error of a futures-based forecast

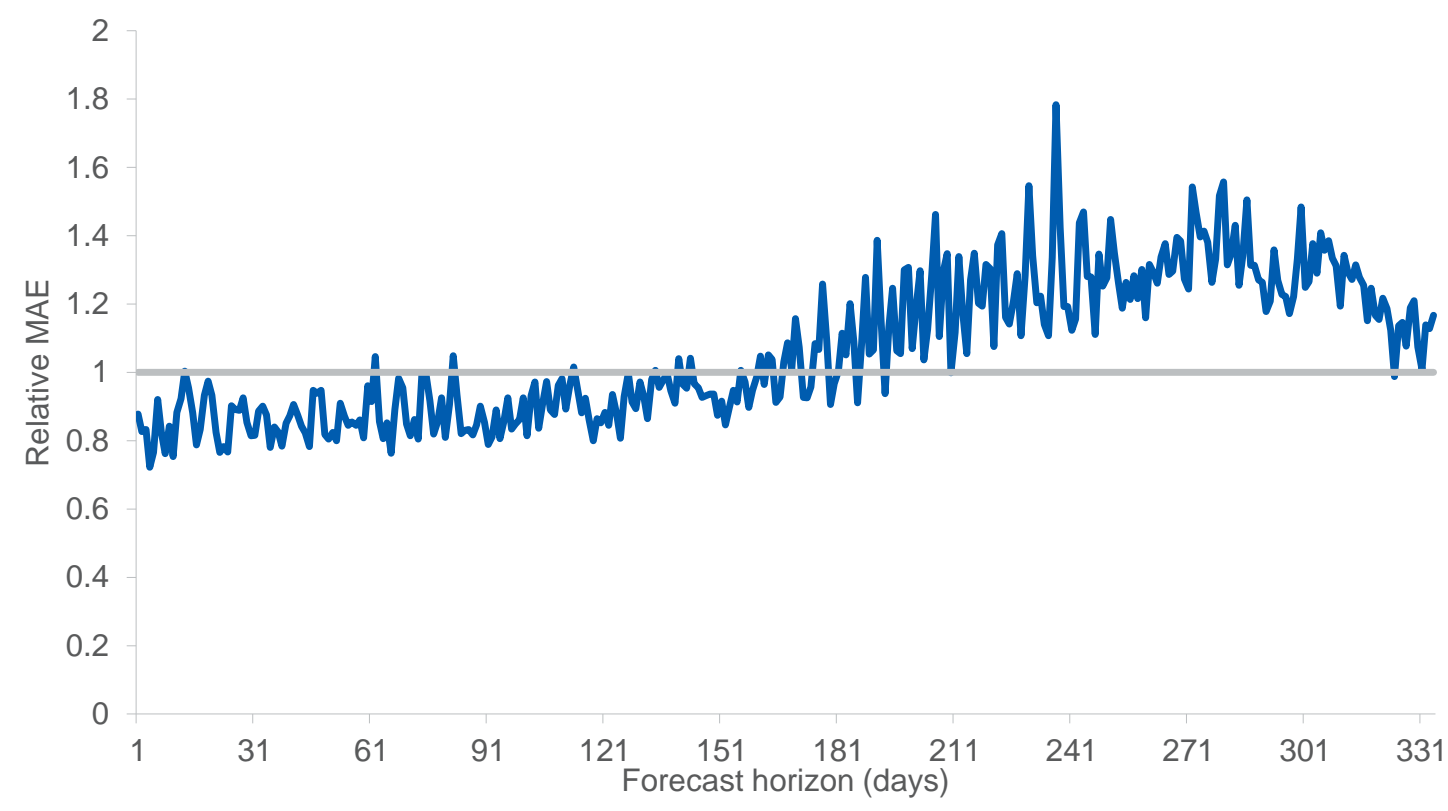

Source: Argus, Bloomberg, author's calculations

Figure 3 shows futures-based forecasts for a number of different time horizons on a rolling basis compared with actual prices. The 30-day and 60-day forecasts picked up the general trend in spot price movements, although they missed just how steeply prices climbed during the 2016-17 and 2017-18 northern hemisphere winters and during the recovery in spot prices from mid-2018. They also failed to anticipate the downturn in spot prices from late 2018. Forecasts for time horizons of over 150-days failed to anticipate most price movements, although they picked up some of the recovery in prices from mid-2018. 

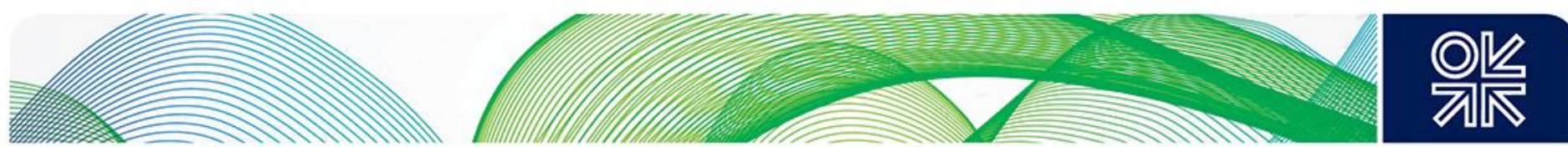

Figure 3: Rolling futures-based forecast at selected time horizons (days)

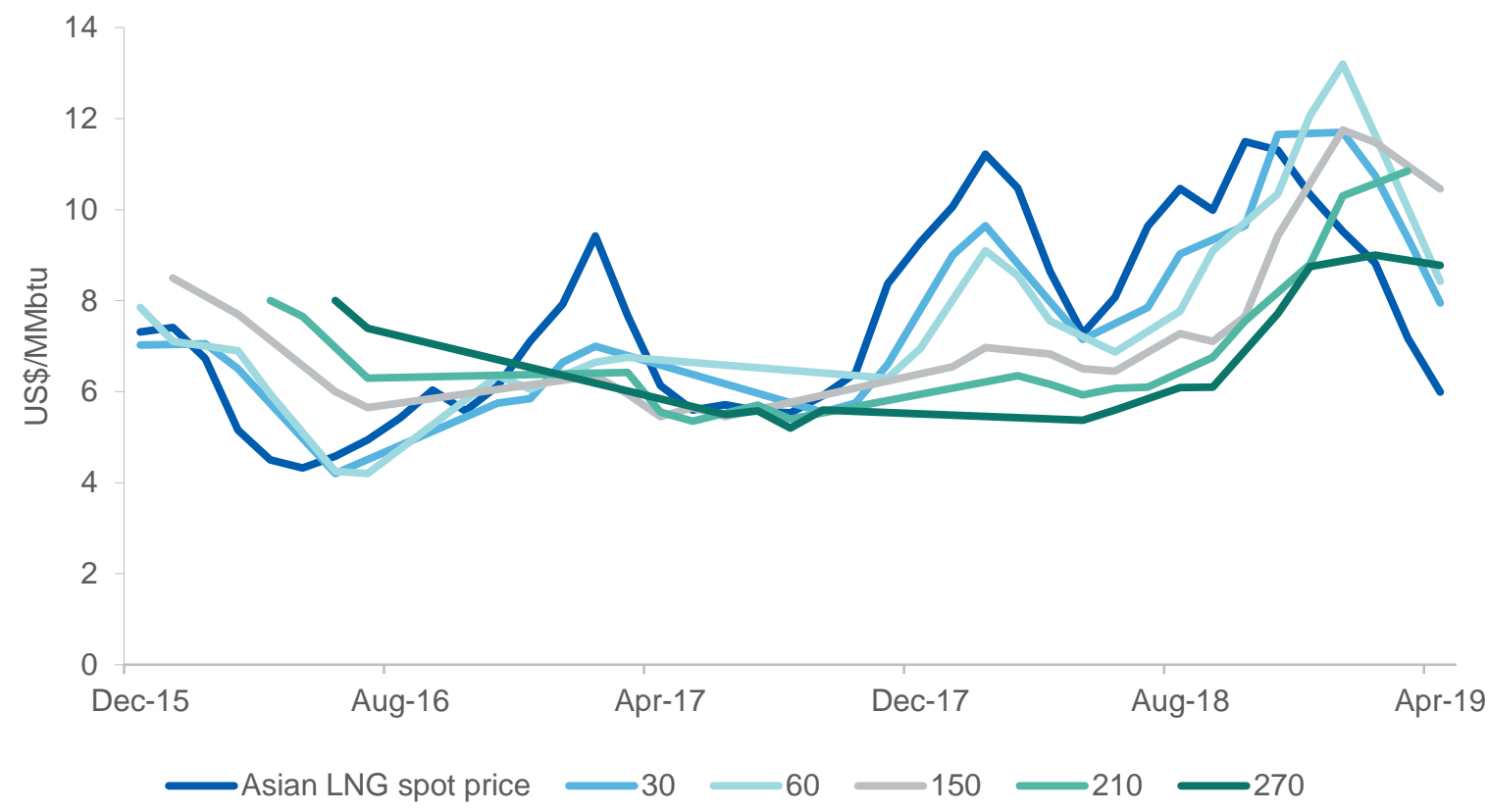

Source: Argus, Bloomberg, author's calculations

Notes: Forecasts and settlement price for each contract month are shown. It is worth noting that the chart understates the accuracy of a futures-based approach, given that futures-based forecasts for different time horizons were not available for some contract months and interpolation was used in these instances.

There are several reasons why a futures-based forecast may perform better over shorter-time horizons. The most basic point is that market expectations of future supply and demand conditions are less reliable further into the future; there are simply more unknowns over longer time horizons.

Another explanation may have to do with the sharp decline in liquidity in the LNG futures market (i.e. the volume of trading activity) after around six months, approximately the same time the futures-based forecast becomes less accurate than the naïve approach. This decline in trading activity may prevent the futures price from accurately capturing market expectations of future LNG spot prices. In other words, declining liquidity may impede the futures market from reflecting all available information about future LNG spot prices. Figure 4 shows the number of open LNG futures contracts on the New York Mercantile Exchange on selected dates, and the decline in trading activity after around six months.

In general, LNG futures markets in Asia remain relatively illiquid, at least compared to a number of other futures markets. By way of comparison, open interest at the time of writing stood at around US $\$ 3$ billion for JKM futures on the Intercontinental Exchange (ICE), compared with US\$10 billion for natural gas futures at National Balancing Point (also ICE), US $\$ 33$ billion for Henry Hub natural gas futures (NYMEX) and US $\$ 145$ billion for Brent oil futures (ICE). However, Figure 4 also shows how the amount of liquidity in the LNG futures market has been increasing rapidly. If a lack of liquidity is a reason for declining forecast accuracy, then the futures curve may become a more useful forecast moving forward.

The declining accuracy of a futures-based forecast may also be driven by an increasing risk premium. The risk premium model, outlined in Section 2, splits the futures price into the expected spot price at the maturity of the futures contract and a risk premium - the return investors require for taking on the risk of exposure to commodity price fluctuations over the term of the futures contract. In general, buyers and sellers need to pay a higher premium to hedge their risk in the futures market as the time to the maturity of futures contracts lengthens. As such, the risk premium could be a source of growing bias in a futures-based forecast. 

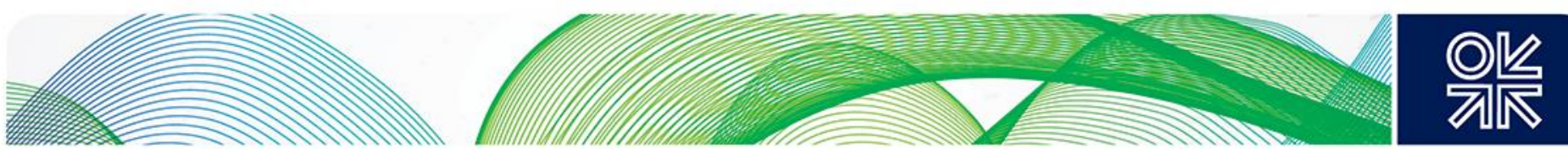

Figure 4: Open futures contracts on the New York Mercantile Exchange on selected dates

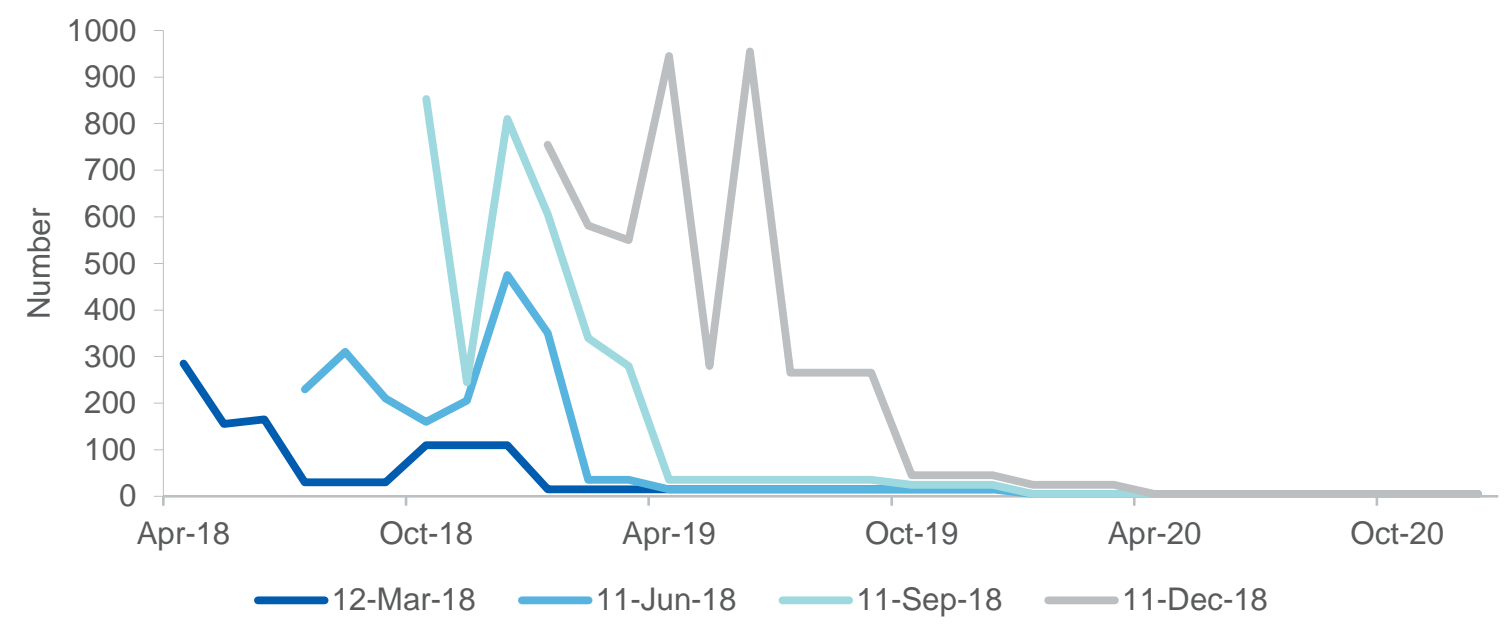

Source: Bloomberg

Notes: Open contracts are futures contracts that have been entered into and not yet settled.

Figure 5 shows the LNG futures curve on selected dates and helps to explain why the futures-based forecast has not been as accurate as the naïve forecast for time horizons of six months or more. The futures curve during the 2016-17 northern hemisphere winter price spike failed to pick up much of the winter price volatility over 2017-18, while the futures curve during northern winter 2017-18 did not capture the price rally from mid-2018. Futures-based forecasts at the end of 2018 also overshot considerably, with LNG spot prices falling sharply from late 2018.

In contrast, the naïve forecast picks up much of this price volatility. While the peaks of the two winter price rallies were roughly a year apart, the back end of the winter 2016-17 price rally is only separated from the front end of the 2017-18 price rally by around six months. The price rally over mid-2018 is picked up by naïve forecasts from six months earlier during the 2017-18 winter price spike.

Figure 5: Asian LNG futures curves on selected dates and Asian LNG spot prices

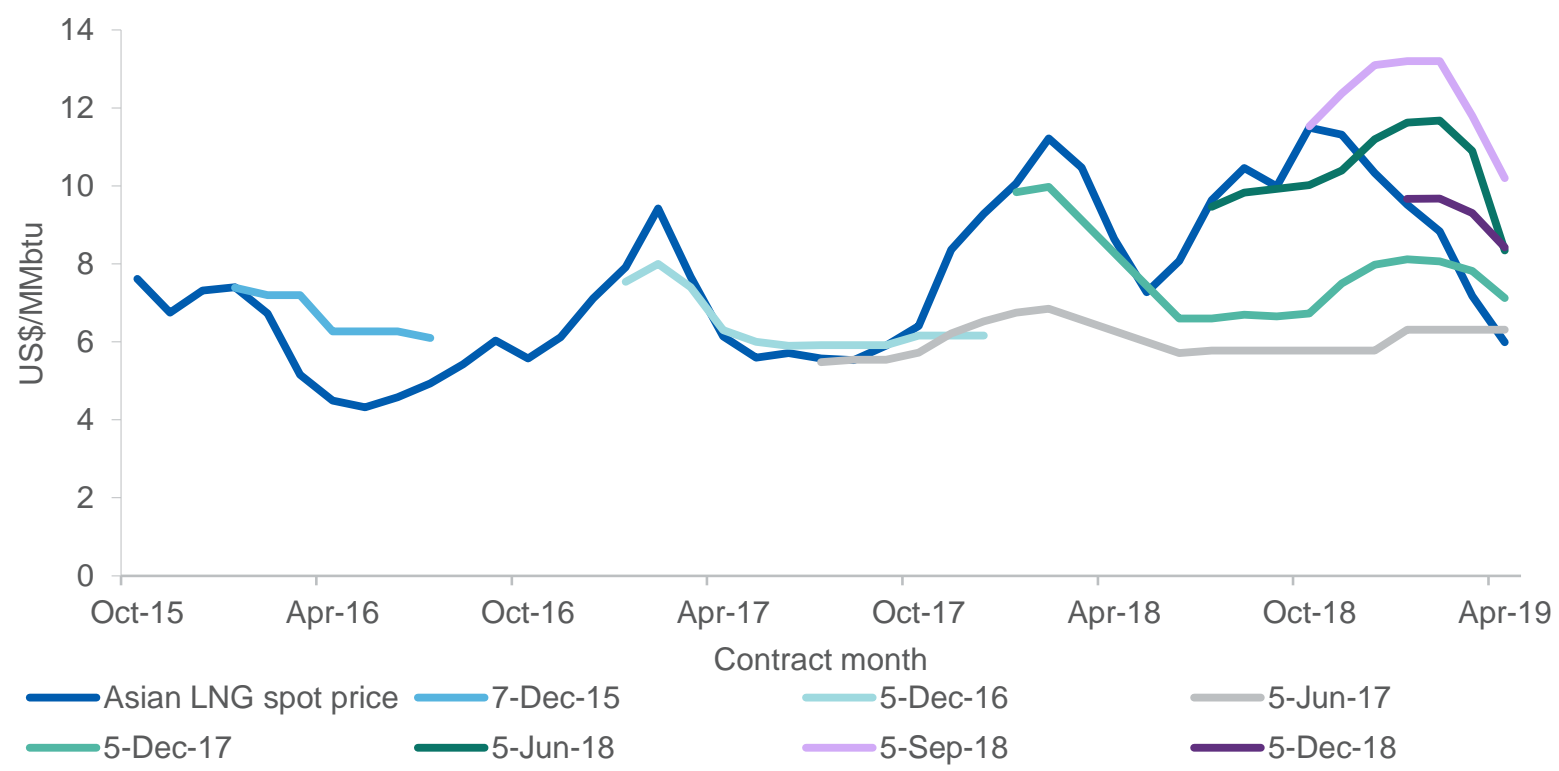

Source: Argus, Bloomberg, author's calculations

Notes: Forecasts and settlement price for each contract month are shown. 

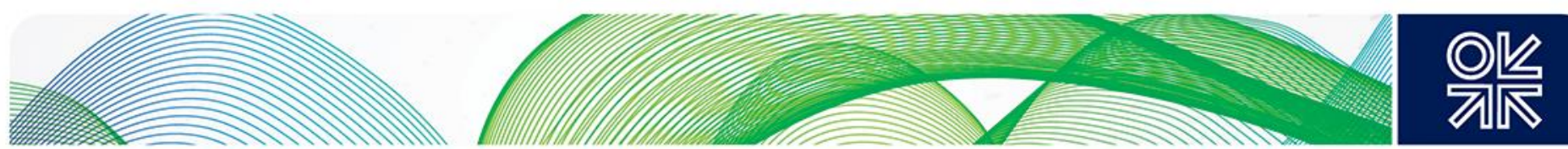

\section{Contango versus backwardation}

The accuracy of the futures-based forecast relative to the naïve is, on average, much better when the futures curve is in backwardation than when it is in contango. Figure 6 shows the relative mean absolute error of the two forecast approaches when the futures curve is in contango compared to when it is in backwardation.

The poor performance of the futures curve in contango is largely because the futures curve pointed to a lift in LNG spot prices in Asia in the lead up to the northern hemisphere winter of 2018-19, when LNG spot prices began a sharp descent. In the results, these recent forecast errors have offset the fact that the futures curve detected the upward movement in spot prices during the 2016-17 and 2017-18 northern hemisphere winters.

These average results, however, obscure the fact that the futures curve has often correctly predicted upward movements in LNG spot prices. When the futures curve is in contango, it is frequently a better forecast than the naïve, especially at time horizons of less than two months. Figure 7 shows the frequency with which the futures-based forecast beats the naïve forecast in contango and backwardation market structures as a percentage. The result suggests that the futures curve may frequently contain information about near-term market tightness.

\section{Figure 6: Relative mean absolute error of a futures-based forecast, backwardation versus contango ${ }^{7}$}

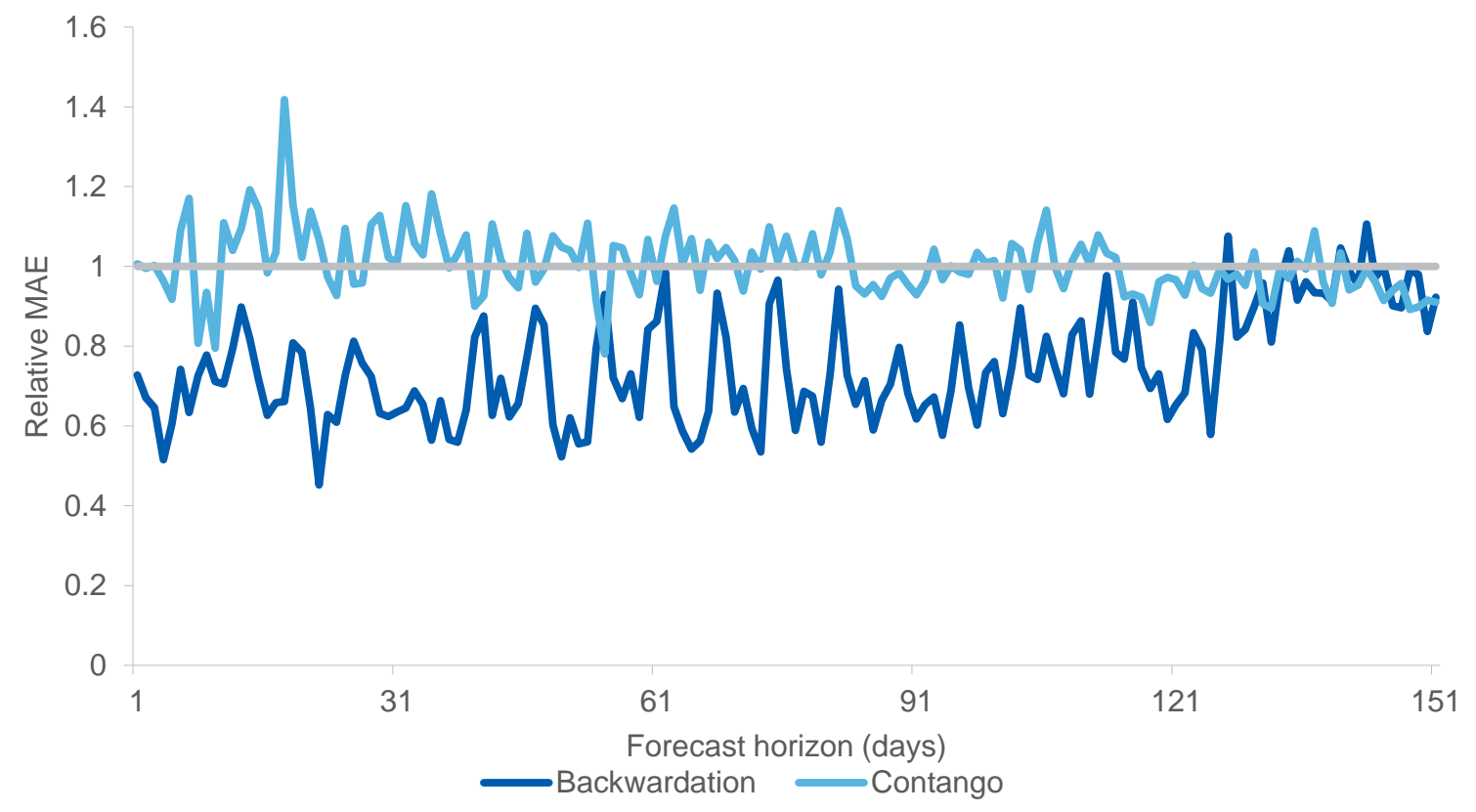

Source: Argus, Bloomberg, author's calculations

\footnotetext{
${ }^{7}$ The forecast errors of the futures-based approach when the futures curve is in contango are compared with forecast errors from the naïve forecast when the futures curve is in contango, rather than with the naïve forecast errors from both backwardation and contango market structures. The same approach has been taken for the purposes of calculating the relative absolute error when the futures curve is backwardated.
} 

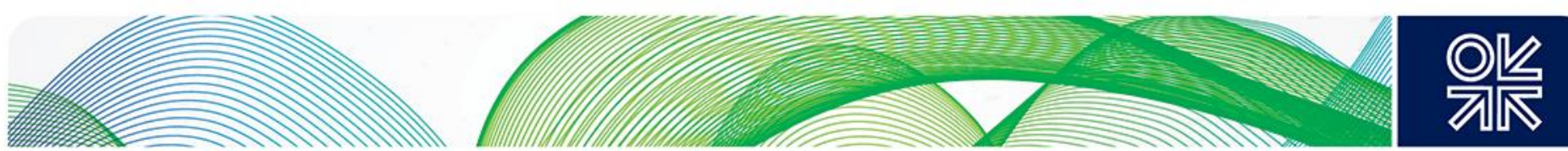

Figure 7: Percentage of futures-based forecasts that beat the naïve forecast

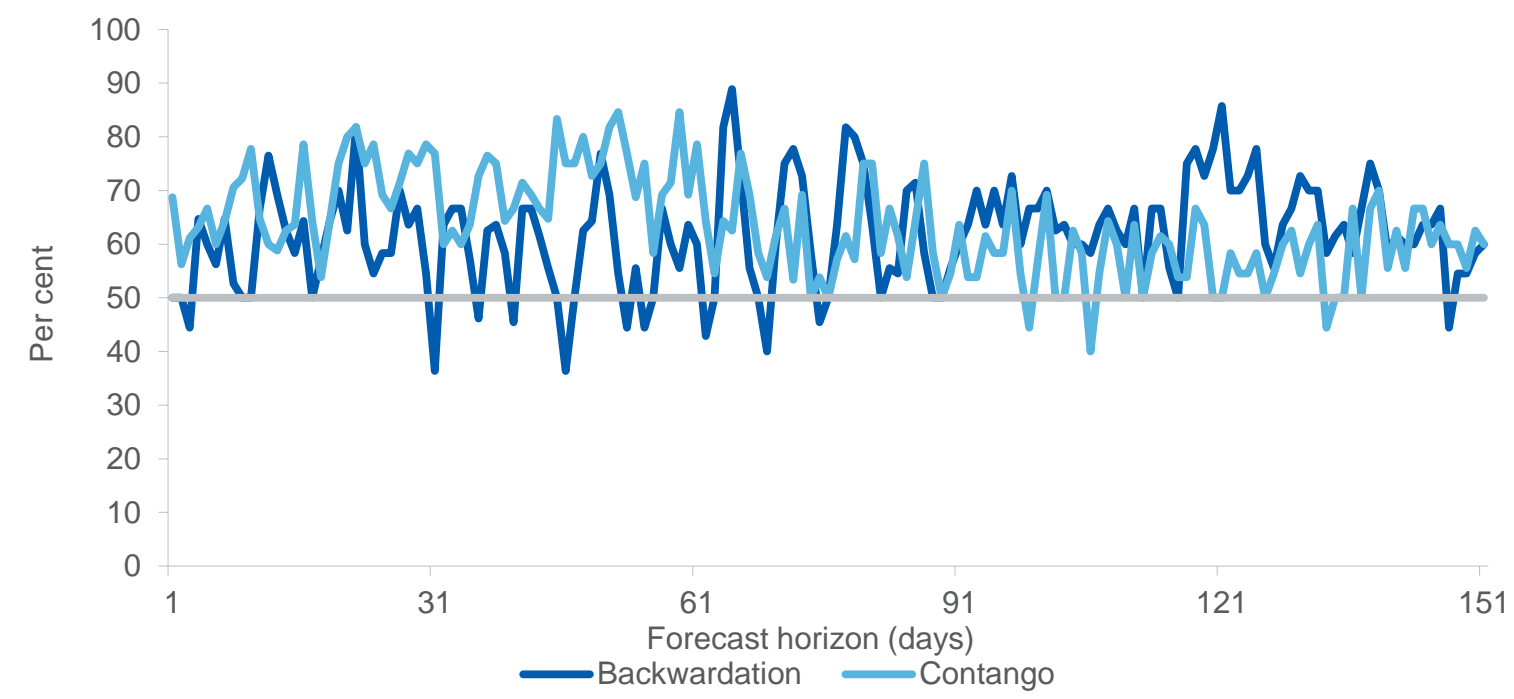

Source: Argus, Bloomberg, author's calculations

Notes: Per cent better measure of forecast error (see Section 3 for further details).

\section{Absolute errors}

Measuring forecasting performance is a relative exercise. Nevertheless, it is important to take stock of the accuracy of futures-based forecasts in absolute terms in order to understand the extent to which they can be relied on as an indication of future price movements.

Figure 8 shows the average difference in both percentage and dollar terms between the futures-based forecast and the actuals. For forecast horizons of under a month, the futures-based forecast records an average error of between roughly US $\$ 0.50-U S \$ 1.00 / \mathrm{MMBtu}$, and this error climbs to around US $\$ 2.00 / M M B t u$ after around five months. For forecast horizons of under a month, this represents an average forecast error of 5-15 per cent of the price, while the forecast error approaches 30 per cent around the five-month mark.

Figure 8: Mean absolute error and mean absolute percentage error of a futures-based forecast

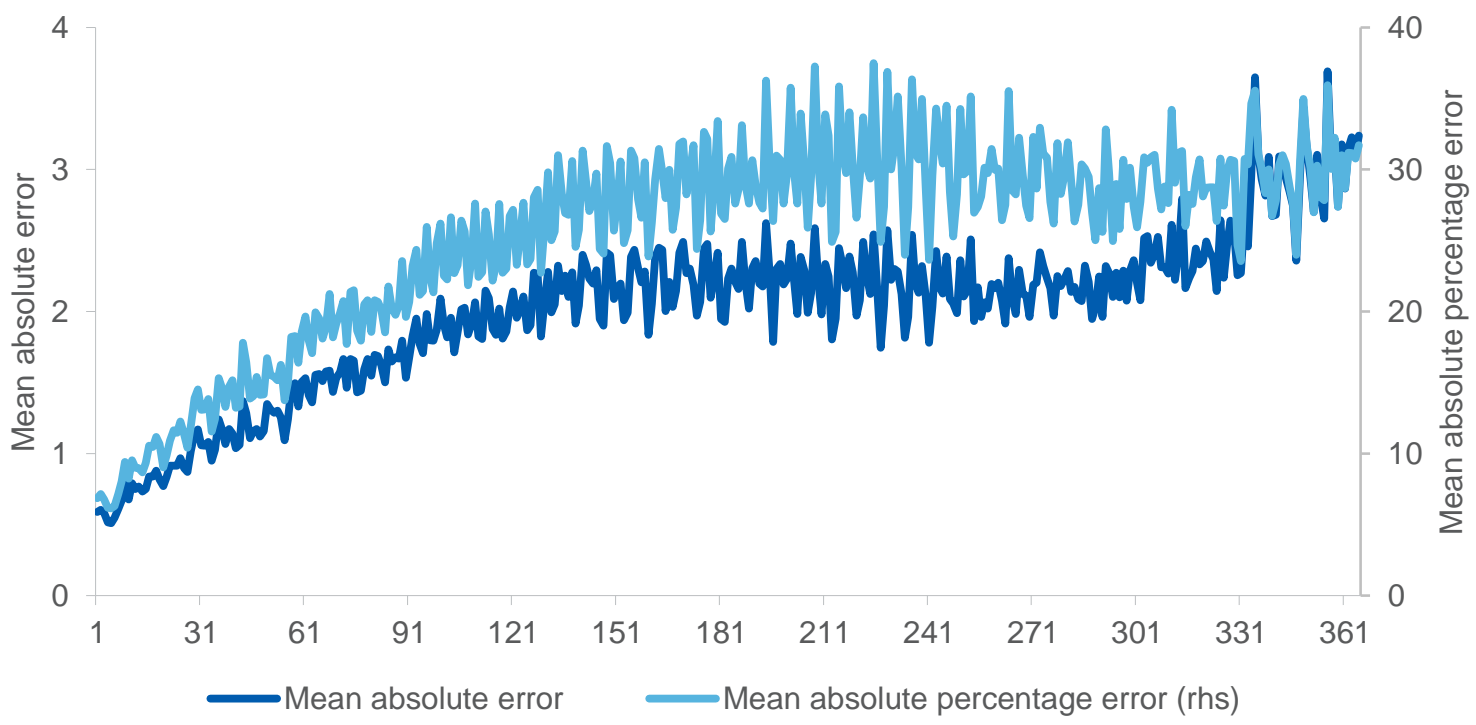

Source: Argus, Bloomberg, author's calculations 

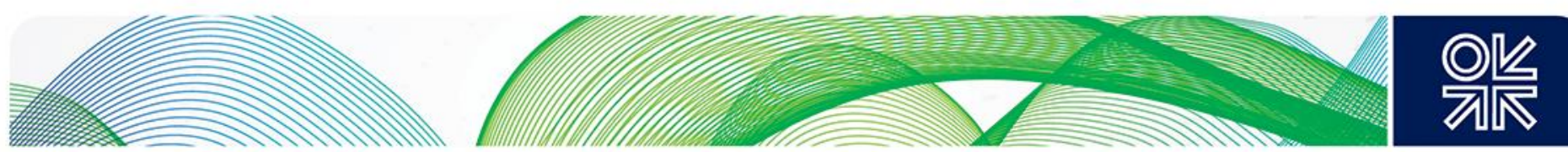

\section{Confidence interval}

Based on the analysis of historical forecast errors in this paper, it is possible to construct a confidence interval that gives a sense of the uncertainty associated with a futures-based forecast. Figure 9 provides a confidence interval around a futures-based forecast for the next five months (the period for which the futures-based forecast outperforms the naïve). Under the assumption that errors are normally distributed, there is a 68 per cent chance that actual prices will fall within the forecast range (Reserve Bank of Australia 2012). While the confidence interval is relatively narrow over first few months of the forecast period, it quickly widens thereafter. The wide range of possible outcomes at a relatively low confidence level suggests that significant uncertainty still surrounds a futures-based forecasting approach.

\section{Figure 9: Confidence interval (68 per cent) around a futures-based forecast ${ }^{8}$}

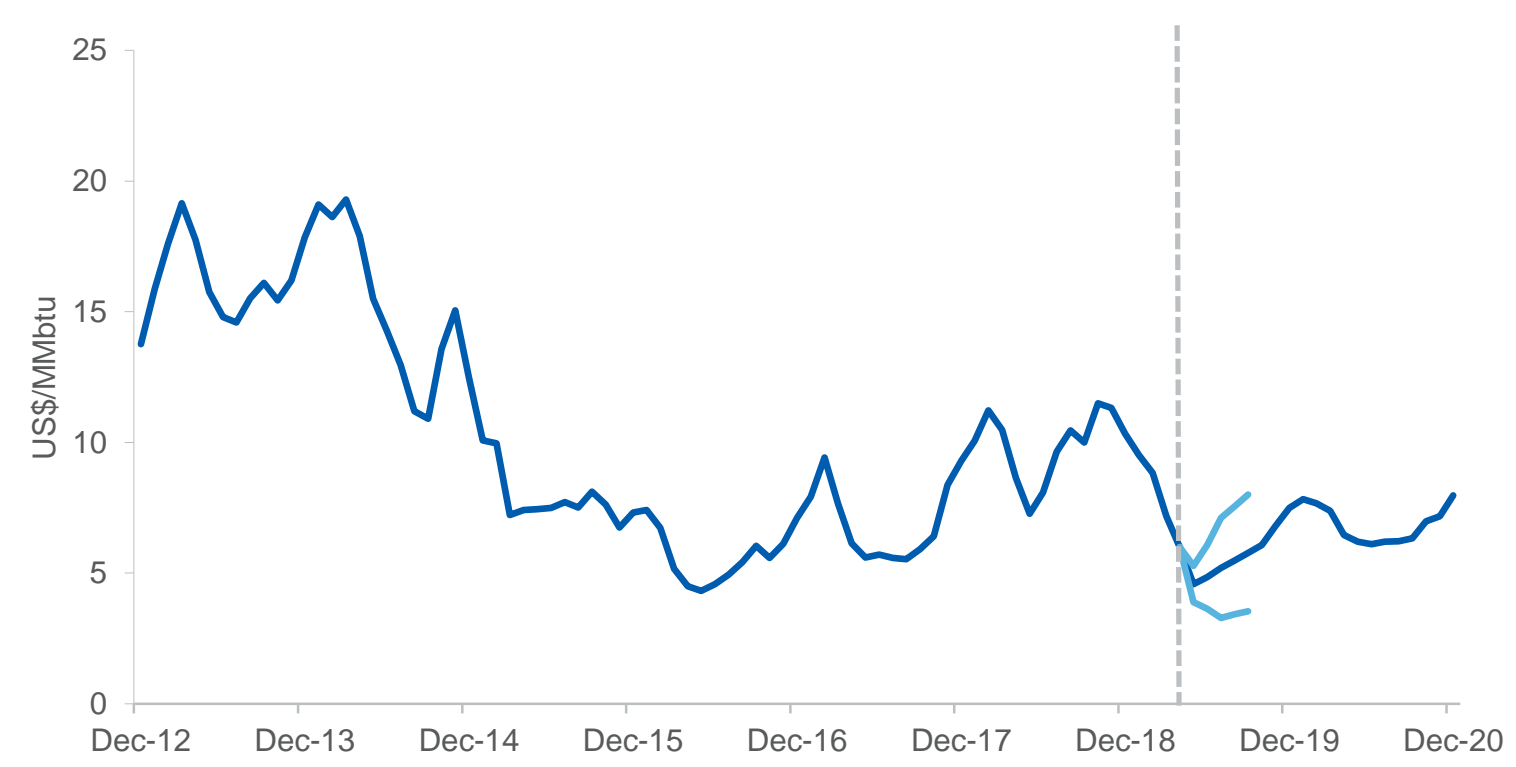

Source: Argus; author's calculations

Notes: Forecasts and settlement price for each contract month are shown.

\section{Conclusion}

The analysis presented in this paper suggests that the Asian LNG futures price can be a useful tool for forecasting the Asian LNG spot price over a time horizon of five months or less, outperforming the literature benchmark naïve forecast for the same period. Average forecast errors when the futures curve is in backwardation are significantly lower than for a naïve forecast, while average errors when the futures curve is in contango are comparable to those of a naïve forecast. However, this is not to say that the futures curve contains no information when it is in contango. At time horizons of two months of less, the futures curve is more frequently a better forecast than the naïve, suggesting that it can sometimes be a useful indicator of a tightening market.

\footnotetext{
${ }^{8}$ It seems unlikely that LNG spot prices could decline as far as suggested by the confidence in this chart, given that prices were near record lows at the time of writing. The lower bound of the confidence interval would be more applicable at higher prices, but the width of the confidence interval is still informative as a general illustration of the uncertainty around a futures-based forecast.
} 

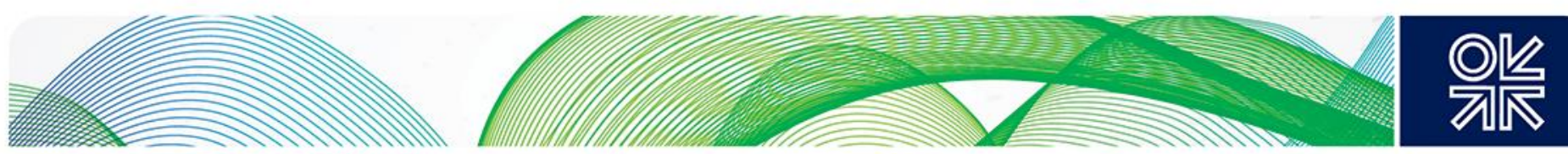

For forecast horizons longer than six months, a naïve forecast outperforms the futures-based forecast. The deterioration in the predictive power of the futures curve may have to do with the concurrent decline in liquidity in Asian LNG futures markets and/or the increasing premium required to hedge risk over longer time horizons - both prevent the futures price from accurately reflecting the market's expectation of future spot prices.

If a lack of liquidity in Asian LNG futures markets is part of the reason that futures prices perform poorly for longer time horizons, the accuracy of the futures curve for forecasting LNG spot prices may improve in coming years as futures trade grows. However, uncertainties inherent in forecasting prices over longer time horizons are likely to set limits on the predictive power of the futures curve. Overall, the results of this paper suggest that the futures curve can provide some insight into future price developments in Asia. 

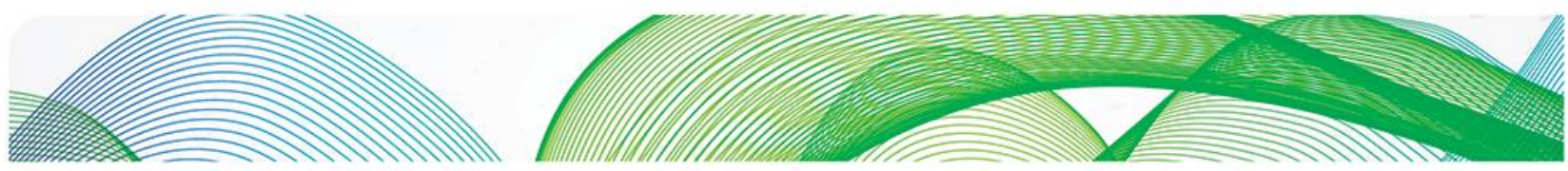

\section{임}

\section{Abbreviations}

$\mathrm{AE}$

ANEA

$\mathrm{Bcm}$

CME

$\mathrm{EMH}$

FID

ICE

JKM

LNG

MAPE

MAE

MMBtu

NYMEX

PB

RMSE

RHS
Absolute Error

Argus Northeast Asian

Billion cubic metres

Chicago Mercantile Exchange

Efficient Market Hypothesis

Final investment decision

Intercontinental Exchange

Japan/Korea Marker

Liquefied Natural Gas

Mean absolute percentage error

Mean absolute error

Million British thermal units

New York Mercantile Exchange

Per cent better

Root mean squared error

Right hand side 

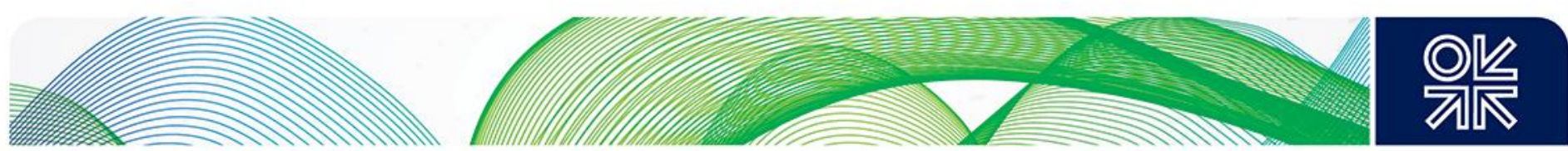

\section{References}

Algieri, B. and Kalkuhl, M. (2014). 'Back to the futures: an assessment of commodity market efficiency and forecast error drivers', ZEF Discussion Papers on Development Policy, no. 195.

https://papers.ssrn.com/sol3/papers.cfm?abstract id=2509820

Alquist, R. and Kilian, L. (2010). 'What do we learn from the price of crude oil futures', Journal of Applied Econometrics, vol. 25 no. 4, 539-573.

Alquist, R., Kilian, L. and Vigfusson, R. J. (2011). 'Forecasting the price of oil', International Finance Discussion Papers, no. 1022. https://www.federalreserve.gov/pubs/ifdp/2011/1022/ifdp1022.pdf

Armstrong, J. S. (2001). 'Evaluating forecasting methods', Marketing Papers 146, University of Pennsylvania, https://repository.upenn.edu/cgi/viewcontent.cgi?article=1182\&context=marketing papers

Armstrong, J. S. and Collopy, F. (1992) 'Error measures for generalizing about forecasting methods: empirical comparisons', International Journal of Forecasting, vol. 8, 69-80.

Australian Government, Department of Industry, Innovation and Science 2017, 'Resources and Energy Quarterly December: Gas'.

https://publications.industry.gov.au/publications/resourcesandenergyquarterlydecember2017/docume nts/Resources-and-Energy-Quarterly-December-2017-Gas.pdf

Australian Government, Department of Industry, Innovation and Science 2018, 'Resources and Energy Quarterly September: Gas'.

https://publications.industry.gov.au/publications/resourcesandenergyquarterlyseptember2018/docume nts/Resources-and-Energy-Quarterly-September-2018-Gas.pdf

Bloomberg New Energy Finance 2017, 'Global LNG Outlook 2017: BNEF's long-term forecast of LNG markets to 2030'. https://data.bloomberglp.com/bnef/sites/14/2017/09/BNEF-Global-LNG-Outlook2017.pdf

Bopp, A. E. and Lady, G. M. (1991). 'A comparison of petroleum futures versus spot prices as predictors of prices in the future', Energy Economics, vol. 4 issue 13, 274-282.

Bowman, C. and Husain, A. M. (2004). 'Forecasting commodity prices: futures versus judgment', Working Paper 04/41, International Monetary Fund.

https://www.imf.org/external/pubs/ft/wp/2004/wp0441.pdf

Chernenko, S. V., Schwarz, K. B. and Wright, J. H. (2004). 'The information content of forward and futures prices: market expectations and the price of risk', International Finance Discussion Papers, no. 808. https://www.federalreserve.gov/pubs/ifdp/2004/808/ifdp808.pdf

Chinn, M. D. and Coibion, O. (2014). 'The predictive content of commodity futures', The Journal of Futures Markets, vol. 34 no. 7, 607-636.

CME Group 2019, 'Glossary', CME Institute. https://www.cmegroup.com/education/glossary.html Corbeau, A. and Flower, A. (2016). 'The maturing of the LNG business', in Corbeau, A. and Ledesma, D. (ed.), LNG markets in transition: the great reconfiguration, Oxford University Press, Oxford, 44-95.

FGE 2016, 'The new dynamics of global LNG industry'. http://www.business.uwa.edu.au/ data/assets/pdf file/0006/2851872/Fereidun-Fesharaki.pdf

Flower, A, and Liao, J. (2012). 'LNG pricing in Asia', in Stern, J (ed.), The pricing of internationally traded gas, Oxford University Press, Oxford, 338-374.

GIIGNL 2019, 'Annual Report'. https://giignl.org/publications

Hambur, J. and Stenner, N. (2017). 'Financialisation and the term structure of commodity risk premiums', Reserve Bank of Australia, Research Discussion Paper 2017-03, 1-32.

Henderson, J., Jensen, J. and Corbeau, A. (2016). 'Future LNG supply: looking ahead, who will be the main potential LNG suppliers?' in Corbeau, A. and Ledesma, D. (ed.), LNG markets in transition: the great reconfiguration, Oxford University Press, Oxford, 209-306. 

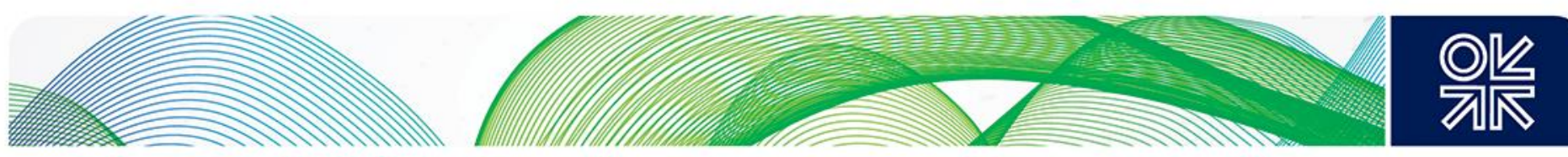

Hyndman, R. J. and Koehler, A. B. (2006). 'Another look at measures of forecast accuracy', International Journal of Forecasting, vol. 22, pp. 679-688.

Jin, X. (2016). 'Does the future price help forecast the spot price?', University of Aberdeen, Discussion Paper in Economics, No. 16-8, 1-40.

http://aura.abdn.ac.uk/bitstream/handle/2164/6276/DP 16 8.pdf?sequence=1

Knetsch, T. A. (2007). 'Forecasting the price of crude oil via convenience yield predictions', Journal of forecasting, vol. 26 no. 7, 527-549.

Macdonald-Smith, A. (2017). 'LNG oversupply to last until 2027: Macquarie', The Australian Financial Review, 6 December. https://www.afr.com/business/energy/gas/Ing-oversupply-to-last-until-2027macquarie-20171205-gzzjw3

Macquarie Wealth Management 2017, 'Australian oil and gas: oversupply set to linger'. https://www.macquarie.com.au/dafiles/Internet/mgl/au/apps/retail-newsletter/docs/201702/AustralianOilAndGas030217e.pdf

Mishra, V. and Smyth, R. (2016). 'Are natural gas spot and futures price predictable?', Economic modelling, no. 54, 178-186.

Movassagh, N. and Modjtahedi, B. (2005). 'Bias and backwardation in natural gas futures prices', The Journal of Futures Markets, vol. 25, no. 3, 281-308.

Reeve, T. A. and Vigfusson, R. J. (2011) 'Evaluating the forecasting performance of commodity futures prices', International Finance Discussion Papers, no. 1025. https://www.federalreserve.gov/pubs/ifdp/2011/1025/ifdp1025.pdf

Reichsfeld, D. A. and Roache, S. K. (2011). 'Do commodity futures help forecast spot prices', IMF Working Paper 11/254. https://www.imf.org/external/pubs/ft/wp/2011/wp11254.pdf

Tulip, P. and Wallace, S. (2012). 'Estimates of uncertainty around the RBA's forecasts', Reserve Bank of Australia 2012, Research Discussion Paper 2012-07.

https://www.rba.gov.au/publications/rdp/2012/pdf/rdp2012-07.pdf

Westerlund, J., Norkute, M. and Narayan, P. K. (2014) 'A factor analytical approach to the efficient futures market hypothesis', Deakin University of Australia. Financial Econometrics Series 2014/12. https://www.deakin.edu.au/ data/assets/pdf file/0005/411917/2014 12.pdf 